\title{
Speech Act of Correction: The Way Iranian EFL Learners Correct their Teachers
}

\author{
Reza Pishghadam \\ Ferdowsi University of Mashhad, Iran \\ Email:pishghadam@um.ac.ir \\ Paria Norouz Kermanshahi \\ Ferdowsi University of Mashhad, Iran \\ Email: paria.pk@stu-mail.um.ac.ir
}

\begin{abstract}
The major aim of this study was to explore how Iranian EFL learners correct their teachers when they make mistakes in class. A sample of 180 English learners from different language institutes took part in this research and completed a questionnaire which proposed a situation in which a teacher makes a mistake and the learners' reaction is investigated. Based on the frequency or percentage of the options selected by the participants, it was confirmed that age, gender and level of proficiency do not have any profound effect on teacher correction, i.e. no matter what the gender, age or proficiency level is, Iranian EFL learners tend to be implicit in their reactions to teachers' mistakes and prefer to remove a harsh tone by adding a softener. Moreover, the results obtained from Iranian EFL learners were compared to those of Americans and Japanese and it was confirmed that their corrective behavior is similar.
\end{abstract}

Index Terms - corrective feedback, speech act, teacher correction, cross-cultural comparison

\section{INTRODUCTION}

One of the salient objectives in ELT classrooms is to enable learners to communicate in the target language. This aim is not fully achieved unless the sociocultural context of the second language is also taken into consideration, because learning isolated words and phrases will never serve the communicative purpose (Cohen, 1996).

A major field of discourse which has been applied to second language acquisition is 'speech acts'. Since learners are obliged to utilize speech acts in nearly all interactions, they must be taught not only how to produce but also how to interpret and comprehend a speech act utterance; if not, they may know well what someone says, but not be able to understand it (Johnstone, 2008). However, performance of speech acts, frequency of their use and strategies applied for realizing them all vary greatly among different cultures; so, both sociolinguistic and sociocultural ability of learners must be given heed to by EFL/ ESL teachers in language classrooms to foster communication. One of the speech acts which requires to be investigated and has been left somehow untouched is 'the speech act of correction'.

Therefore, in this study we are about to explore how Iranian EFL learners correct teachers if they make a mistake and whether they differ in their speech acts if their age, gender, proficiency level or culture change.

\section{THEORETICAL FRAMEWORK}

As James (1980) states, the teacher's role is to monitor and assess learners' performance to know why errors are committed and then to provide corrective feedback- that is responses to learners' produced utterances which "repair" or "call attention" to their errors (Brown, 2007, p. 379). As brown argues, for the corrective feedback to be efficacious, it must be 'optimal' i.e. when there are too many corrections, learners may make no more attempts to communicate, and when there are very few corrections, it may lead to fossilization. Therefore, in order to make the best out of correction, Vigil and Oller (1976), offered a model known as 'Communicative Feedback Model' which helps teachers in approaching learners' errors in language classrooms.

Learners consider correction as a source of improvement (Chaudron, 1988), but it is the teacher who determines what is the best type of correction, when is the most proper time for that, and whether to correct or not. There are different types of correction (Brown, 2007; Celce-Murcia, 2001):

a) Explicit/ Direct: When the teacher indicates an error and supplies the correct form (Brown, 2007);

b) Implicit/ Indirect: When the teacher points out the problem and asks the learner to correct it if possible (Richards \& Schmidt, 2002);

c) Self-correction: It helps learners in "pushing their output in the direction of improved accuracy" (Swain, 1985, as cited in Celce-Murcia 2001, p. 274);

d) Peer-correction: When other learners cannot understand or when they see someone 'gets stuck' (Paulston \& Bruder, 1976); 
e) Recast: When the teacher repeats learners' ill-formed utterance with a minute change in form (Brown, 2007);

f) Clarification request: When the learner is asked to repeat or reformulate (Brown, 2007);

g) Metalinguistic feedback: When the teacher gives comments and information or asks questions (Brown, 2007);

h) Elicitation: When the teacher gives a prompt to help learners self-correct (Brown, 2007);

i) Repetition: When the teacher repeats what the learner had said with a change in intonation (Brown, 2007).

Whatever the type of correction will be, students will respond in different ways; their reaction to the received feedback from teachers is called 'uptake' (Richards \& Schmidt 2002). As Lyster and Ranta (1997, p.49) put it, uptake is "a student's utterance that immediately follows the teacher's feedback and that constitutes a reaction in some way to the teacher's intention to draw attention to some aspect of the student's initial utterance". Therefore, when a learner produces an erroneous utterance, the teacher provides feedback and the learner responds to it; this may also be applicable to teachers being corrected by learners.

Besides copious research done on speech acts in English, there are various cross-cultural studies which aimed at comparing and contrasting English speech acts with those of other languages such as Persian, Chinese, Japanese, Spanish, and Turkish. Speech acts such as request (e.g. Kılıçkaya 2010, Jalilifar 2009), compliment (e.g. Grossi 2009, Tang \& Zhang 2008), apology (e.g. Shariati \& Chamani 2009, Afghari 2007), refusal (e.g. Chang 2008, Ken, Lin \& Tseng 2006), complaint (e.g. Young 2008, Umar 2006) and disagreement (e.g. Guodong \& Jing 2005) have been dealt with so far.

To know how teachers treat learners' errors is of paramount importance. Piles of studies are available which investigate teachers' corrective feedback either to find a relationship between learners' errors and teachers' response or to pinpoint a correlation between error correction and accuracy, motivation or acquisition. For instance, observing patterns of error treatment in ESL classrooms, Panova and Lyster (2002) tried to find a relationship between feedback type and learners' response. Many researchers highlighted the type of correction favored by teachers and learners and concluded that teachers prefer indirect correction (Ellis, Basturkmen \& Loewen, 2001). Some other studies examined correction in writing such as Vickers and Ene (2006) who concluded that self-correction is the best in writing since it leads to greater grammatical accuracy.

In nearly all studies on correction or corrective feedback, it is brought into focus that error correction has a social dimension, which means any criticism or praise will both be public (Allwright, 2005). Therefore, according to Szextay (2004), teachers need to think deeply when they correct a learner in order not to make them feel "absolutely stupid" and to "maintain rapport".

All the mentioned points depend on the speech act of correction used by teachers when correcting a learner or vice versa. However, to our knowledge, only one study was done to analyze the speech act of correction in depth, more significantly to compare it with correction in another culture and focus on learner correction as well. Takahashi and Beebe (1993) examined American and Japanese performance of the speech act of correction with unequal power status. They studied the use of positive remarks and softeners to make each speech act less face-threatening and to make communication smoother. In fact, they were about to observe the effect of power and distance of addresses on subjects' choice of expression, and to compare them in two different languages.

Before dealing with the methodology they adopted and the results they obtained, it is necessary to define some key terms used in their research. They clarified the distinction between softeners and positive remarks which seems to be blurred.

As Takahashi and Beebe (1993, p. 144) state, positive remarks include praise, compliments and positive evaluation; grammatically speaking, a positive remark is "a preceding adjunct which is phrasal and separate from the main body". (e.g. It was a good presentation, but ...)

Softeners, on the other hand, are "down-toning devices integrated in the main body of speech acts". In fact, softening devices are categorized into three groups (Takahashi \& Beebe, 1993, p. 142):

1) Softeners (e.g. I believe, I think, You may have ...)

2) Questions (e.g. Did you say ...?)

3) Expressions to lighten the gravity of the mistake or to defend the interlocutor (e.g. You made one small error in ...).

Takahashi and Beebe (1993) selected two different power relations, higher to lower and lower to higher and through discourse completion tasks, compared American and Japanese in these two situations. They concluded that in the first situation (higher to lower status), 64\% of Americans speaking English preferred correction with at least one positive remark. e.g. That was very good, but I believe ...

English speaking Japanese never prefaced their responses with positive remarks except $23 \%$ who used something resembling them. e.g. Your idea is fine, but I think the ...

Japanese using Japanese used even fewer positive remarks. e.g. Wait a second, the date is incorrect ...

Therefore, they concluded that the three groups are arranged as follows:

$\mathrm{AE}>\mathrm{JE}>\mathrm{JJ}$

AE: Americans using English

JE: Japanese using English

JJ: Japanese using Japanese 
They claimed that the Japanese use less positive remarks because it is verbal and they show no interest in verbal expressions by nature. The tone also varied between them; the Japanese used an authoritative tone and more directives.

In the second situation (lower to higher status), however, the results were totally reversed:

$\mathrm{JJ}>\mathrm{JE}>\mathrm{AE}$

Takahashi and Beebe (1993) concluded that: first, the Japanese who use English transfer some style shifting patterns from their L1. Second, using a positive remark when correcting someone of lower status is an American pattern and the Japanese rarely use it.

\section{PURPOSE OF THE STUDY}

As it was mentioned, it seems that a great deal of research has been carried out in other realms of speech acts including refusals, requests, apologies, compliments, complaints etc. However, the speech act of correction had remained somehow untouched, excluding merely one research done by Takahashi and Beebe (1993).

Moreover, there are plenty of studies (e.g. Panova \& Lyster, 2002; Vickers \& Ene, 2006) which studied the issue of corrective feedback, all focusing on types, time and methods of correction, or the relationship between correction and learners' performance in the four skills (reading, writing, speaking and listening). However, none of these studies highlighted the speech act through which a teacher or a learner corrects and whether it makes any changes if they add softeners and positive remarks or not.

Therefore, paucity of research in this realm makes this particular study significant with the chief purpose of delving into ELT classrooms to discern how EFL learners correct their teachers, whether the speech act of correction differs when changing the power status changes, whether males and females apply the same speech acts for correction and to compare Iranians' performance with that of Americans and the Japanese to figure out sociocultural differences if there are any.

\section{METHOD}

\section{A. Setting and Participants}

A community sample of 180 EFL learners participated in this study, comprising 90 males and 90 females aged between 15 and 45 i.e. 90 teenagers and 90 adults. They were all EFL learners studying in language institutes in Mashhad, a city in Iran with different social economic backgrounds.

In this study, age, gender, proficiency level and culture are the four variables whose effects were to be observed. First, to determine the role of proficiency level in the speech act of correction, the sample comprised EFL learners of three different levels- starter, intermediate and advanced. Second, the present study seeks to figure out whether age plays any crucial role in the corrective behavior or not; so among the participants 90 are adults and 90 are teenagers. Third, a salient point to be investigated in this research is the role of gender in the use of speech act of correction; hence, the participants are 90 males and 90 females. At the end, how culture makes differences in the speech act of correction is momentous to the researchers. However, since there is no access to participants of a different culture, the results are compared to those of Takahashi and Beebe (1993) as to compare and contrast Iranian, American and Japanese learners.

\section{B. Instrumentation}

As Cohen (1996) believes, one of the straightforward methods for gathering data on speech acts is through discourse completion questionnaires which will gather a lot of data at full pelt.

Participants in this study were required to complete a questionnaire which was designed based on the guidelines provided by Takahashi and Beebe (1993) and personal teaching experiences. There is a situation where a mistake is made by the teacher and the participants must pen how they would respond to it. Six options ranging from implicit to explicit were provided to aid the participants, and a space to write their opinions if it they were not included (See Appendix).

The content validity of this questionnaire was substantiated through a pilot study in which 60 EFL learners took part. On the recommendations of an expert in this field and based on the feedback received from participants, questions were revised and ambiguities were removed.

\section{Procedure}

The process of data collection started in October (2010), beginning of a new semester in language institutes, and ended in December (2010) after 3 months. The designed questionnaire was distributed among 180 EFL learners in different language institutes. Their classes were interrupted for 5 minutes by kind permission of their teachers; some instructions and needed guidance were provided by the researchers before responding. Then the participants had about 3 minutes to read the situation and options and to decide on their responses. The questionnaires were collected afterwards to be analyzed.

The options selected by the respondents were transformed into tables displaying the frequency and percentage of each, and the tables were analyzed qualitatively through comparing and contrasting the options. Three tables were 
compiled, each focusing on one of the variables under study. The participants of each group - males and females, adults and teenagers, starter, intermediate and advanced learners - were compared and the results were discussed.

At the end, Iranians' performance was compared to that of Americans and Japanese to figure out whether sociocultural differences bring about variations in the speech act of correction.

\section{RESULTS}

In situation 1, learners are asked to pen what they would say if a teacher makes a mistake in answering a question. Considering the participants, there are three different variables to be examined (gender, age, proficiency level) and in this situation, six options to be checked off. The options contain both implicit and explicit answers and for the first part of the analysis, we are to demonstrate whether females' and males' teacher-correction differs, and if it does what the differences are. Which group tends to correct more explicitly/implicitly is to be investigated here.

TABLE 1

FREQUENCY AND PERCENTAGE OF ANSWERS TO EACH OPTION CONSIDERING GENDER

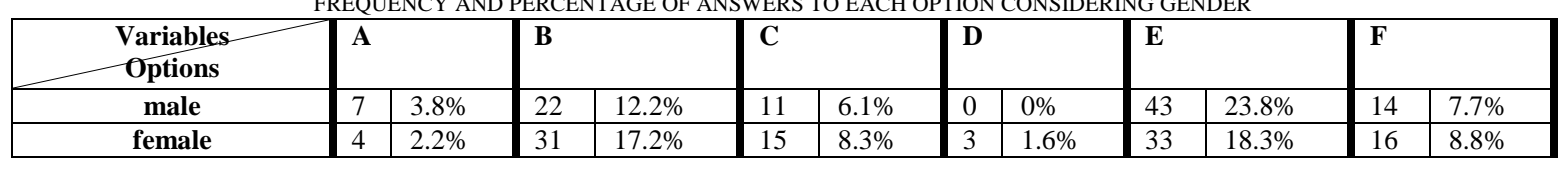

As it is indicated in Table 1, most of males (23.8\%) and females (18.3\%) preferred option 'E':

I think the answer is (c), am I wrong?

This option seems not only to be implicit but also contains 'softeners' or 'down-toning devices' such as "I think" (Takahashi \& Beep, 1993, p. 142). Hence, we can infer that both male and female EFL learners prefer to correct implicitly and at the same time they tend to remove a harsh tone through the application of hedges.

The second most favored option is 'B'; $12.2 \%$ of males and $17.2 \%$ of females selected this option which is again an indirect reply and just casts doubt on the provided answer, but does not propose any answer:

Are you sure (b) is correct?

The least number of participants opted for options 'A' and ' $\mathrm{D}$ '. Among males merely $3.8 \%$ selected option A and no one checked off option D; among females $2.2 \%$ opted for A and $1.6 \%$ for D. That being the case, $3.8 \%$ of males and $2.2 \%$ of females tended not to correct at all. And interestingly, no males and $1.6 \%$ of females (the least percentage) went for ' $D$ ' which seemingly taunts the teacher with his/her failure:

You mean (c), don't you?

According to Table 1, there is no meaningful relationship between gender and teacher correction; both males and females were of the same opinion in responding to the situation, though the frequencies of responses differ. Therefore, the results are summarized as follow:

TABLE 2

FREQUENCY AND PERCENTAGE OF ANSWERS TO EACH OPTION CONSIDERING AGE

\begin{tabular}{|l|l|}
\hline Males & $\mathrm{E}>\mathrm{B}>\mathrm{F}>\mathrm{C}>\mathrm{A}>\mathrm{D}$ \\
\hline Females & $\mathrm{E}>\mathrm{B}>\mathrm{F}>\mathrm{C}>\mathrm{A}>\mathrm{D}$ \\
\hline
\end{tabular}

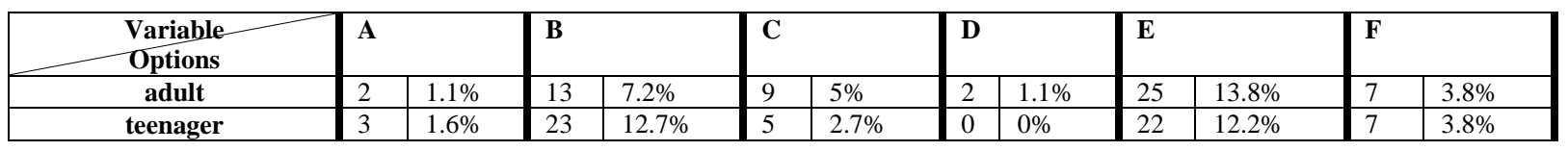

Since the second variable under study is age, we were to examine whether or not it played any crucial role in the way learners correct teachers. As demonstrated in Table 2, option ' $\mathrm{E}$ ' is again selected by most of the participants (13.8\% adults and $12.2 \%$ teenagers). It is concluded that no matter what the gender or age is, Iranian EFL learners tend to be implicit in their reactions to teachers' mistakes and prefer to add a softener as well.

The percentage of teenagers opting for options ' $\mathrm{B}$ ' and ' $\mathrm{E}$ ' is almost the same though there is merely a minute difference ('B': $12.7 \%$ and ' $\mathrm{E}$ ': $12.2 \%$ ). Therefore, there is no clear-cut distinction between adults and teenagers in selecting ' $\mathrm{E}$ ' and ' $\mathrm{B}$ '. However, the next favored option by adults is ' $\mathrm{C}$ ':

Isn't it (c)?

This seems to be the most straight-forward reaction which is not prefaced with any kind of softeners; $5 \%$ of adults preferred this option which is almost double the percentage achieved by teenagers, $2.7 \%$. Hence, it is inferred that comparing adults and teenagers, adults seem to react in a more forthright manner.

Option ' $F$ ' is selected by exactly the same number of adults and teenagers $(3.8 \%)$ though considering rank, it is the fourth for adults and the third for teenagers:

I'd go to the teacher after the class and say: why wasn't part (c) correct?

An issue similar to 'delayed correction' is involved here. However, when teachers apply later correction, they are to prevent interruption caused by correction, so when the focus is on fluency, they prefer delayed correction. In this 
situation, learners are about to correct teachers and those who select this option are the ones who have at least the intention of correction but postpone it to a later time after the class.

Among adults, the same number of participants opted for options ' $A$ ' and ' $D$ ' $(1.1 \%)$, while in teenagers $1.6 \%$ selected ' $\mathrm{A}$ ' and no one checked off option ' $\mathrm{D}$ '. That being the case, $1.1 \%$ of adults and $1.6 \%$ of teenagers tend not to correct at all. And interestingly no teenagers and $1.1 \%$ of adults (the least percentage) go for ' $\mathrm{D}$ ' which taunts the teacher.

The summary of the results obtained thorough Table 2 is provided below.

TABLE 3

FREQUENCY AND PERCENTAGE OF ANSWERS TO EACH OPTION CONSIDERING LEVEL OF PROFICIENCY

\begin{tabular}{c|l} 
Adults & $\mathbf{E}>\mathrm{B}>\mathrm{C}>\mathrm{F}>\mathrm{A} / \mathrm{D}$ \\
\hline Teenagers & $\mathbf{B}>\mathrm{E}>\mathrm{F}>\mathrm{C}>\mathrm{A}>\mathrm{D}$ \\
\hline
\end{tabular}

\begin{tabular}{|c|c|c|c|c|c|c|c|c|c|c|c|c|}
\hline $\begin{array}{l}\text { Variable } \\
\text { Options }\end{array}$ & \multicolumn{2}{|c|}{$\mathbf{A}$} & \multicolumn{2}{|l|}{ B } & \multicolumn{2}{|l|}{$\mathbf{C}$} & \multicolumn{2}{|c|}{ D } & \multicolumn{2}{|l|}{$\mathbf{E}$} & \multicolumn{2}{|l|}{$\mathbf{F}$} \\
\hline starter & 2 & $1.1 \%$ & 16 & $8.8 \%$ & 9 & $5 \%$ & 2 & $1.1 \%$ & 31 & $17.2 \%$ & 10 & $5.5 \%$ \\
\hline intermediate & 3 & $1.6 \%$ & 23 & $12.7 \%$ & 5 & $2.7 \%$ & 0 & $0 \%$ & 22 & $12.2 \%$ & 7 & $3.8 \%$ \\
\hline advanced & 6 & $3.3 \%$ & 14 & $7.7 \%$ & 12 & $6.6 \%$ & 1 & $0.5 \%$ & 23 & $12.7 \%$ & 13 & $7.2 \%$ \\
\hline
\end{tabular}

Casting a look at Table 3, we deduce that again almost the highest frequency in each level belongs to option ' $E$ ' (17.2\% starter, $12.2 \%$ intermediate, $12.7 \%$ advanced). No matter what the gender, age or proficiency level is, Iranian EFL learners tend to be implicit in their reactions to teachers' mistakes and prefer to remove a harsh tone by adding a softener. Overall, the three null hypotheses are confirmed.

Moreover, the second favored option is similarly ' $\mathrm{B}$ ' in all three levels except among intermediate learners who selected ' $\mathrm{B}$ ' slightly more than ' $\mathrm{E}$ ' which is not a noteworthy distinction $(12.7 \%$ ' $\mathrm{E}$ ', $12.2 \%$ ' $\mathrm{B}$ ').

The third selected option with high frequency is ' $F$ ' in all levels (5.5\% starter, $3.8 \%$ intermediate, $7.2 \%$ advanced). This indicates that at any proficiency level, learners mostly prefer to be indirect at the first onset (option E), or to cast doubt on the provided answer in an implicit way (option B), and if not, they are inclined to postpone the correction to a later time (option F).

The rest of the options are in the same sequence as before and therefore the same discussion is applicable. Here are the summary of the results considering the proficiency level of learners:

\begin{tabular}{|c|c|}
\hline Starter & $\mathbf{E}>\mathrm{B}>\mathrm{F}>\mathrm{C}>\mathrm{A} / \mathrm{D}$ \\
\hline Intermediate & $\mathbf{B}>\mathrm{E}>\mathrm{F}>\mathrm{C}>\mathrm{A}>\mathrm{D}$ \\
\hline Advanced & $\mathbf{E}>\mathrm{B}>\mathrm{F}>\mathrm{C}>\mathrm{A}>\mathrm{D}$ \\
\hline
\end{tabular}

\section{DISCUSSION}

Based on the analysis of the data, age, gender and proficiency level do not have any profound effect on teacher correction, i.e. no matter what the gender, age or proficiency level is, Iranian EFL learners tend to be implicit in their reactions to teachers' mistakes and prefer to remove a harsh tone by adding a softener. Besides being indirect, most learners prefer to add hedges such as 'I think' to their responses, and they very rarely taunt the teacher with his/her failure.

The obtained results are greatly dependent on the educational context in which learners are acquiring English. In Iran, there is a depersonalized and formal relationship between teachers and students, for instance, learners are seldom called by their first names especially at the school and university, and they almost never call the teacher by first name either. The teacher has a formal dominant role in class and as a result, the power status plays a crucial role in every aspect. Moreover, due to the existence of religious views, teachers' job in Iran is considered equal to that of prophets, and therefore teachers are considered to be very scared and highly respected. Overall, there may sometimes be a friendly relationship between a teacher and a learner, though it is often a formal and distant one.

The results of the current study confirm those of Takahashi and Beeb (1993). They studied the speech act of correction among three groups of participants and concluded that all three groups of participants preferred to preface their responses with softeners and hedges, though the percentage of the used softeners differs among them: JJ >JE >AE (Takahashi \& Beeb, 1993). Hence, Iranian EFL learners, Americans using English, Japanese using English and Japanese using Japanese are the same in correcting teachers: they all prefer to add softeners when they correct, demonstrating that there is a universal trend among English learners. There exist some differences as well, for instance, from 180 participants of our study, merely 11 participants $(6.1 \%)$ preferred not to correct the teacher; however, $40 \%$ of JJ, $20 \%$ of JE and $13 \%$ of AE opted out in that study (Takahashi \& Beeb, 1993).

The results of this study suggest several implications; first, it will bring about consciousness raising of teachers by making them aware of teacher correction and will also let them know that there might be cross-cultural differences of correcting teachers. Second, this study examined whether sociocultural differences affect the speech act of correction or 
not. Hence, it will be of great importance to cross-cultural studies which aim to compare different cultures and figure out the sources of cross-cultural miscommunication or failure. Moreover, materials developers can benefit from the findings of the current research. A multitude of books are published on the subject of correction every now and then, each devoting a whole chapter to correction, mentioning which errors to correct and which ones to ignore, but never focusing on learner correction.

Considering the interlocutors, there are three types of correction which can be done by learners: teacher correction, peer correction and self correction. In this research, we examined the first type among Iranian EFL learners and compared them with other groups. More studies are needed to investigate learners' reactions in other two situations as well.

\section{APPENDIX}

$\begin{array}{lll}\text { Female } & \mathrm{O} & \text { age } \ldots \ldots \ldots \\ \text { Male } & \mathrm{O} & \text { Level } \ldots \ldots \ldots\end{array}$

What would you do/say in this situation?

You are a student in an English class. Your teacher makes a mistake in answering a question related to a reading text; instead of (c) he/she says (b).
A) I would probably say nothing.
B) Are you sure (b) is correct?
C) Isn't it (c)?
D) You mean (c), don't you?
E) I think the answer is (c), am I wrong?
F) I'd go to the teacher after the class and say: why wasn't part (c) correct?

Something else:

\section{REFERENCES}

[1] Afghari, A. (2007). A sociopragmatic study of apology speech act realization patterns in Persian. Speech Communication, 49 (3), 177-185.

[2] Allwright, D. (2005). From teaching points to learning opportunities and beyond. TESOL Quarterly, 39 (1), 9-31.

[3] Brown, H.D. (2007). Principles of language learning and teaching (5th ed.). White Plains, NY: Pearson Education.

[4] Celce-Murcia, M. (Ed.). (2001). Teaching English as a second or foreign language (3rd ed.). New York: Heinle \& Heinle.

[5] Chang, Y. F. (2008). How to say no: An analysis of cross-cultural difference and pragmatic transfer. Language Sciences, 31 (4), 477-493.

[6] Chaudron, C. (1988). Second language classrooms: Research on teaching and learning. Cambridge: Cambridge University Press. In M. Celce-Murcia, (Ed.). (2001). Teaching English as a second or foreign Language (3rd ed.). New York: Heinle \& Heinle.

[7] Cohen, A. D. (1996). Speech acts. In McKay, S. L., \& Hornberger, H. N. (Eds.). (1996). Sociolinguistics and language teaching. New York: Cambridge University Press.

[8] Ellis, R., Basturkmen, H., \& Loewen, S. (2001). Preemptive focus on form in the ESL classroom. TESOL Quarterly, 35 (3), 407-432.

[9] Grossi, V. (2009). Teaching pragmatic competence: Compliments and compliment responses in the ESL classroom. Prospect, 24 (2), 53-62.

[10] Guodong, L., \& Jing, H. (2005). A contrastive study on disagreement strategies for politeness between American English and Mandarin Chinese. Asian EFL Journal, 7 (1), 1-12.

[11] Jalilifar, A. (2009). Request strategies: cross-sectional study of Iranian EFL learners and Australian native speakers. English Language Teaching, 2 (1), 46-61.

[12] James, C. (1980). Contrastive analysis. Singapore: Longman.

[13] Johnstone, B. (2008). Discourse analysis (2nd ed.). Malden, MA: Blackwell Publishing.

[14] Ken, C., Lin, S., \& Tseng, Y. (2006). To refuse - the art of saying "no". Retrieved June, 5, 2010, from http://www.shs.edu.tw.

[15] Kilıçkaya, F. (2010). The pragmatic knowledge of Turkish EFL students in using certain request strategies. Sosyal Bilimler Dergisi, 9 (1), 185-201.

[16] Panova, I., \& Lyster, R. (2002). Patterns of corrective feedback and uptake in an adult ESL classroom. TESOL Quarterly, 36 (4), 573-595.

[17] Lyster, R. \& Ranta, L. (1997). Corrective feedback and learner uptake. Studies in Second Language Acquisition, 20 , 37-66.

[18] Paulston, C. B., \& Bruder, M. N. (1976). Teaching English as a second language: Techniques and procedures. Cambridge, Massachusetts: Winthrop Publishers.

[19] Shariati, M., \& Chamani, F. (2009). Apology Strategies in Persian. Journal of Pragmatics, 42 (6), 1689-1699. 
[20] Richards, J. C., \& Schmidt, R. (2002). Longman dictionary of language teaching and applied linguistics (3rd ed.). London: Pearson Education.

[21] Swain, M. (1985). Communicative competence: Some roles of comprehensible input and comprehensible output in its development. In Celce-Murcia, M. (Ed.). (2001). Teaching English as a Second or Foreign Language (3rd ed.). New York: Heinle \& Heinle.

[22] Szesztay, M. (2004). Teachers' ways of knowing. ELT Journal, 58 (2), 129-136.

[23] Takahashi, T., \& Beebe, L. M. (1993). Cross linguistic influence in the speech act of correction. In Kasper, G., \& Bulm-Kulka, S. (Eds.). (1996). Interlanguage Pragmatics. Oxford: Oxford University Press.

[24] Tang, C. H. E. N., \& Zang, G. Q. (2008). A contrastive study of compliment responses among Australian English and Mandarin Chinese speakers. Journal of Pragmatics, 41 (2), 325-345.

[25] Umar, A. M. A. T. (2006). The speech act of complaint as realized by advanced Sudanese learners of English. Journal of Educational \& Social Sciences \& Humanities, 18 (2), 8-40.

[26] Vickers, C. H., \& Ene, E. (2006). Grammatical accuracy and learner autonomy in advanced writing. ELT Journal, 60 (2), 109116.

[27] Vigill, N., \& Oller, J. (1976). Rule fossilization: A tentative model. Language Learning, 26, 281-295. In Brown, H.D. (2007). Principles of language learning and teaching (5th ed.). White Plains, NY: Pearson Education.

[28] Young, K. D. (2008). A Study of complaint strategies for EFL college learners. Modern English Education, 9 (2), 58-70.

Reza Pishghadam is associate professor in TEFL. He is currently in Ferdowsi University of Mashhad, where he teaches Psychology of language education and Sociology of language education. He has published more than 40 articles and books in different journals. His major interests are: Psychology / Sociology of language education, and Language testing.

Paria Norouz Kermanshai is an MA holder in TEFL. She has done her study in Ferdowsi University of Mashhad. Her major interests are: Psycholinguistics and Teaching methodology. 